The community care grant is considered by most local authorities to be inadequate. Although a specific grant for the mentally ill will be made available through the regional health authorities, early indications are that funding will be inadequate. As a result more acute beds will be taken up by chronically ill patients who would be better cared for in the community.

Napsbury Hospital

Barnet Psychiatric Unit

J. SCHIPPERHEUN

Barnet General Hospital

Barnet EN5 3DJ

Napsbury Hospital

London Colney

Herts AL2 IAA

\section{The social state}

G. IkKos

Dear Sirs

I thought Campbell and Szmukler's proposal for writing up the social state on every case very interesting (Psychiatric Bulletin, January 1993, 17, 4-7). It would emphasise the importance of social factors in the aetiology and prolongation of illness and would be of practical help at care planning meetings with Social Services. I think, however, their list of points is incomplete as it does not give a heading for responsibilities. Some patients relapse, not because of lack of family or contacts, but because of the pressures put upon them by unavoidable responsibilities such as the care of children, elderly or disabled relatives, and I would suggest they expand their framework to take account of this.

University of Bristol

A. C. Brown

Department of Mental Health

Bristol BS2 8DZ

\section{Who acts as the consultant's nominated deputy?}

DeAr Sirs

The article Section 5(2) of the Mental Health Act 1983: Who acts as the consultant's nominated deputy? (Psychiatric Bulletin, 1992, 16, 759-761) highlights problems and uncertainties most junior doctors will face. However, two issues should have been addressed in more detail.

(a) Transfers between hospital sites under Section 5(2) of the Mental Health Act was found to be a problem for example between a peripheral psychiatric unit. While the article was primarily an audit I do feel the opportunity should have been used to resolve the dilemma. As far as I am aware for transfer to another hospital a patient on Section 5(2) would have to be transferred to Section 2 or 3.

(b) Although not categorically stated the audit would seem limited to psychiatric wards. One area that has always created problems is the care of disturbed patients on non-psychiatric wards. It is quite clear from the Mental Health Act that the nominated deputy should be that of the patient's consultant, irrespective of what ward he or she is on. I find that junior doctors in other specialities are extremely hesitant in accepting this responsibility. Perhaps this issue needs to be raised more often in the induction meetings for junior doctors.

Leighton Hospital

HAKEEM KAZEEM

Crewe, Mid Cheshire

C46 $3 R E$

\section{Reply}

\section{DeAR SIRS}

The comments made by Dr Kazeem are similar to those raised by Fuller (1993). The aim of our study was to explore the variation between health districts in the interpretation of who is most suitable to act as the RMO's nominated deputy. As part of the study, comments about difficulties encountered with the use of section 5 were also invited. A very small proportion of respondents had encountered problems with the transfer of patients between psychiatric hospital sites while detained under section 5 . In each case the difficulty had been subsequently resolved. Clearly this is an important issue; however, it is not possible to make a blanket statement to cover all such cases. Inevitably, whether a problem is posed by the transfer (e.g. from a peripheral psychiatric unit to a psychiatric intensive care unit), is dependent upon the structure of local services. If both hospital sites are headed by the same management team as one unit, then the transfer would be within the regulations of the Mental Health Act (1983).

As described in our paper, the study was conducted by sending a seven item questionnaire to the manager responsible for psychiatric services in each district in England and Wales. The study did not undertake to examine the use of section $5(2)$ by nonpsychiatrists. We disagree with Dr Kazeem's statement that it is quite clear who the nominated deputy should be in these cases. Should the nominee of a consultant physician be a junior physician who works for him or her, an on-call junior physician or the on-call consultant physician? Perhaps there is an 
industrious trainee who would wish to study this, maybe by using a project design similar to ours?

SALly-ANN COOPER

RUTH HARPER

Clinical Sciences Building

Leicester Royal Infirmary

Leicester $L E 27 L X$

\section{Reference}

Fuller, G. M. (1993) Section 5(2). (Correspondence) Psychiatric Bulletin, 17, 171.

\section{The British Confederation of Psychotherapists}

\section{Dear Sirs}

In January 1992, ten psychoanalytically oriented organisations met to consider developments taking place in the United Kingdom Standing Conference for Psychotherapy (now the UK Council for Psychotherapy). They were concerned that the diversity of standards and trainings and size of the Analytical Psychotherapy Section (now renamed the Psychoanalytic and Psychodynamic Psychotherapy Section) with its 32 organisations posed insuperable problems to the establishment of appropriate standards for training.

A Working Party was set up to make proposals that would define and protect the training and practice of psychoanalytic psychotherapy and on 8 March The British Confederation of Psychotherapists was formed. It has been agreed that the character of the BCP is best represented by adding to the title: Psycho-Analysts, Analytical Psychologists, Psychoanalytic Psychotherapists and Child Psychotherapists, which comprise the field of psychoanalytic psychotherapy. The member organisations of the $\mathrm{BCP}$ recognise that there are other forms of psychotherapy but consider they are only competent to set standards in relation to the training and practice of psychoanalytic psychotherapy.

The main aim of this organisation is to form a register of psychotherapists who have trained in psychoanalytic psychotherapy and belong to an organisation whose standards of training and code of ethics are sufficiently rigorous to have been approved by the BCP's Registration and Ethics Committee.

The BCP has now completed its main documents. The constitution is being vetted by a lawyer after which the BCP would hope to publish a register and have its documents available for those interested. It can then respond formally to organisations interested in applying for membership.

In the meantime the BCP have made contact with relevant government departments and other professional organisations with an interest in the training and practice of psychotherapy. So far there has been a positive expression of interest from government departments and the professions.

JOSCELYN RICHARDS

Chair of the Shadow Council of Institutions ANNE-Marie SANDLER

Chair of the Shadow Advisory Board

The British Confederation of Psychotherapists

c/o 175 Cheviot Gardens

London NW2 IPY

\section{Psychiatry and the media}

DeAR SIRS

A recent Channel 4 programme in the series The Pulse purported to present a patient with a long history of depression that had not responded to tricyclics or SSRIs.

In fact the gentleman concerned, while from time to time exhibiting depressive symptoms, has a much more serious problem with chaotic substance misuse. Over a number of years he has been seen by all members of the local psychiatric services ranging from psychotherapists, specialist substance misuse staff and more than one psychiatrist; during this time he has continued to misuse alcohol, amphetamines, cannabis, benzodiazepines, LSD and his prescribed medication.

By using such a patient to represent a failure of medical treatment of depression the programme does a great disservice to the millions of people every year who genuinely suffer from depression and their medical attendants (both GPs and psychiatrists) who successfully treat them.

Perhaps this again underlines the necessity to be wary of the programme makers with pre-determined agenda and the need for the profession to take a lead in presenting accurate information to the general public about mental illness and its treatment.

I presume the producers did not ask the College to officially take part in the programme.

Formerly Bassetlaw District General Hospital

Worksop S810BD 